\title{
School-level disadvantage and failed cessation treatment among adolescent smokers
}

\author{
Kimberly Horn' ${ }^{1}$, Maliha Ali ${ }^{2}$, Tiffany Gray ${ }^{2}$, Andrew Anesetti-Rothermel ${ }^{3}$, Steve Branstetter ${ }^{4}$
}

\begin{abstract}
INTRODUCTION While understanding factors that lead to successful adolescent smoking cessation outcomes is necessary, it is also prudent to determine factors and conditions that contribute to failure to quit smoking. The present study posits that adolescents' proximal environments, such as schools, may influence cessation treatment outcomes.

METHODS Using aggregated and geographically-referenced data from multi-year school-based cessation trials with 14-19 year olds seeking cessation in 5 States of the USA, the present study developed and applied a tobacco-specific socio-spatial model inclusive of Hierarchical Linear Modeling. Specifically, this novel approach spatially joined individual data files $(n=8855)$ with measures of school $(n=807)$ and county socio-economic factors. Once linked multi-level analyses explored the extent to which cessation treatment failure was explained by the interplay of individual, school and county-level factors. Treatment was deemed as failing to meet its primary goals if participants continued to smoke cigarettes, measured 3-months post baseline.

RESULTS Ten per cent of the variation in cessation treatment failure was attributable to school-level variables. Adolescent smokers were more likely to experience failure to quit in: a) school districts with large percentages of the population having less than high-school education, and b) schools with a higher ratio of students to teachers. The strength of the relationship between cessation self-efficacy and treatment success was further weakened among adolescents attending schools with higher percentages of students eligible for free or reduced lunch programs.

concLUSIONS Findings implicate school-level socio-economic disadvantage as a significant factor inhibiting cessation, regardless of adolescent self-efficacy to quit smoking. Understanding the interplay of proximal school environments and individual-level factors may provide insights to educators, policy makers and practitioners into the complexities that inhibit or strengthen an adolescent's smoking cessation treatment experience.
\end{abstract}

AFFILIATION

1 Department of Population Health Sciences, Virginia Tech Carilion Research Institute, Virginia, United States 2 Milken Institute School of Public Health, Department of Prevention and Community and Health, George Washington University, Washington, United States 3 Schroeder Institute at Truth Initiative, District of Columbia United States

4 Department of Biobehavioral, Health Pennsylvania State University, United States

\section{CORRESPONDENCE TO}

Kimberly Horn. Department of Population Health Sciences,

Virginia Tech Carilion Research Institute, Virginia, United States. E-mail: kahorn1@vt.edu

\section{KEYWORDS}

adolescents, tobacco use, cessation behavior, school-level determinants, socio-spatial model

Received: 3 November 2017 Revised: 16 March 2018 Accepted: 20 March 2018

\section{INTRODUCTION}

One in four US high-school students currently use some form of tobacco, with $9.3 \%$ of these tobacco users reporting smoking combustible cigarettes in the past 30 days in $2015^{1}$. The onset of smoking before the age of 18 years hastens nicotine dependence, elevating risks for detrimental and lasting effects on the developing brain and sustained tobacco use ${ }^{2}$. Although the percentage of US adolescents reporting combustible cigarette use is at a historic low ${ }^{1}$, with all products combined (e.g. cigars, e-cigarettes, smokeless tobacco), the overall tobacco use prevalence remains unchanged over the past two decades ${ }^{1-5}$. Even though over half of current 
adolescent smokers express a desire to quit, most who seek cessation treatment face numerous challenges and ultimately fail ${ }^{6-8}$.

Despite considerable research on predictors of adolescent tobacco cessation, tobacco control experts continue to grapple with low cessation rates. Youth tobacco cessation rates range between 7-12 $\%^{9,10}$. Adolescent cessation studies conventionally de-emphasize failed treatment rates among cessation seekers, favoring instead to report the predictors of successful cessation outcomes or not reporting outcomes other than complete abstinence. Given the typical focus on individual-level data, underscoring failed outcomes may be perceived as pointing to something innately wrong or lacking with the individual adolescent's capacity to quit. An alternative and novel view, as proposed in this study, is the examination of 'failure' not as failure of the individual adolescent but a failure of the treatment and the treatment environment to meet individual needs or risks. Moreover, while the understanding of individual-level factors related to both successful and failed treatment is important, examination of the interplay of factors beyond the individual that affect treatment outcomes is critical. It is plausible, for instance, that socio-economic factors or a combination of factors, including the occupations, education levels, income and wealth within localities proximal to adolescents may partially explain tobacco use. Research increasingly demonstrates that tobacco use is influenced by a myriad of socio-environmental factors. For instance, studies show notable variation of smoking prevalence rates across schools, regardless of individual-level factors ${ }^{11-13}$, suggesting direct pathways between schools and adolescent tobacco use, tobacco attitudes, and motivation to quit tobacco ${ }^{14-16}$. School-level determinants are known to explain between $4 \%$ to $40 \%$ of the variation in smoking, across both middle and high-school aged students ${ }^{11}$. Many studies also demonstrate that smoking in adulthood is influenced by childhood socio-economic disadvantage ${ }^{17-19}$.

Acknowledging tobacco control as a complex and dynamic system, there have been numerous calls, from policy makers and the research community, to consider a systems perspective that expounds the complex socio-environmental influences of tobacco use $^{20,21}$. Behavioral theories, such as Bronfenbrenner's
Ecological Systems theory ${ }^{22}$, emphasize the role of socio-environmental factors beyond the individual that influence health behaviors. Tobacco users are influenced not only by demographic, biological and psychological factors, but also by external forces such as governments, industries and social environments, including schools, neighborhoods and workplaces. Forces within these environments ${ }^{5,20}$ may influence tobacco use behaviors through macro-scaled strategies, including State tobacco control funding or taxation, tobacco industry marketing, and State or county clean-indoor air regulations ${ }^{3,23-28}$. While conceptual thinking touts the benefits of multilevel synergistic tobacco control initiatives, practical implementation has been slow, in part because the requisite research has not been conducted. The lack of empirical literature describing the application of comprehensive models that capture and account for multi-level influences has impeded real-world application and results. While there is some research showing that adult smoking cessation treatment can be moderated by these strategies ${ }^{29}$, the field knows very little about the relative contribution of these factors on adolescent tobacco cessation. To bridge this literature gap, the present article describes an innovative socio-spatial approach to measure and explain the multi-level socio-environmental influences on adolescent tobacco cessation. By exploring the contributions of socio-environmental risk among adolescents who experience failed treatment it is possible to glean guidance in reducing cessation program failure, especially for adolescents who generally need it the most.

The study goal was to explain how person- and place-based social factors can influence smoking cessation outcomes among adolescents enrolled in a cessation treatment program spanning over a decade in many States. The present research adapted a multilevel socio-ecological model (Figure 1) to examine more specifically the influence of school-level socio-environmental factors, including school-level demographics and economics, on adolescent smoking cessation failure ${ }^{20}$. Analyses also examined the extent to which the school environment moderated the relationship between individual-level predictors (e.g. cessation self-efficacy and number of cigarettes per day) and cessation failure. Secondary data capitalized on various existing sources, including a 
Figure 1. Multi-level model of treatment failure

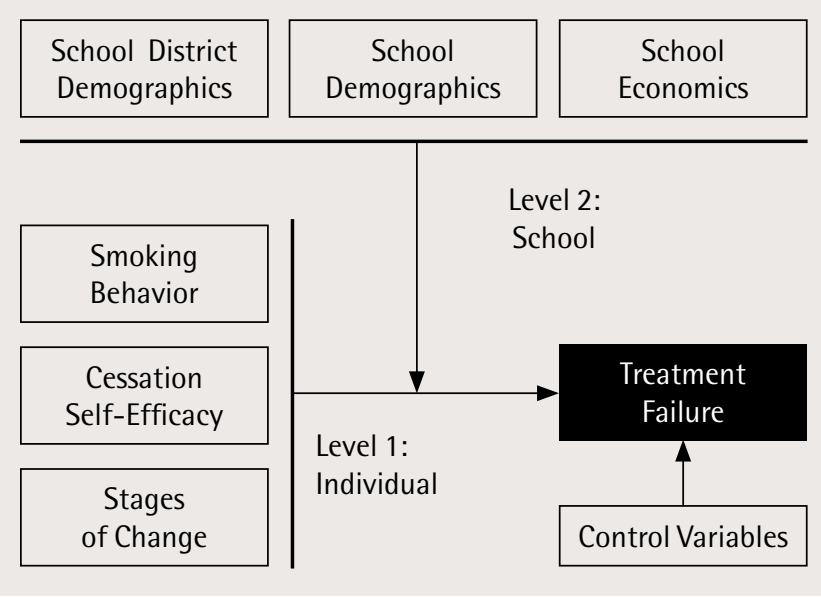

longitudinal-data set obtained from studies of a national school-based adolescent smoking cessation program (American Lung Association's Not-OnTobacco, N-O-T $)^{30-33}$. The environment of focus is the school, as N-O-T delivery historically occurs in schools. Schools are well established important settings for health promotion, including smoking cessation and offering a sustained and effective avenue for reaching the adolescent population.

\section{METHODS}

\section{Data sources}

By linking individual data to geo-referenced schoollevel data, researchers established a tobacco-specific socio-spatial evaluation allowing active consideration of space, place, personal and social indicators on smoking cessation. For the present research aim, two levels of data were used to fulfil our evaluation: individual-level data (Level 1) from adolescent cigarette smokers, and school-level data (Level 2) linked to those individuals through geo-referenced codes. Data on individual-level adolescent smokers $(\mathrm{N}=8855)$ came from de-identified aggregated original sources from 28 separate evaluation trials ${ }^{31}$ from 5 States spanning 1997-2012. Table 1 summarizes the variables in the individual-level and school-level data. Enrolled adolescents sought treatment voluntarily and were enrolled in either brief or intensive treatments (i.e. 10-15 minute one-time advice to quit vs $\mathrm{N}-\mathrm{O}-\mathrm{T}$ ), both treatments had the goal of smoking cessation. In all trials, participants were current smokers $(\geqslant 1$ cigarettes per day or CPD, in past 30 days) and between 14-19 years old. Similar methodology was used across studies including design, instrumentation, recruitment,

\section{Table 1. Key study variables}

\begin{tabular}{|c|c|}
\hline LEVEL I & RESPONSE OPTIONS \\
\hline \multicolumn{2}{|l|}{ Demographics } \\
\hline Age & Ages: 14-19 \\
\hline Grade & Grades:7-12 \\
\hline Race/Ethnicity & $\begin{array}{l}\text { White; African American; American Indian; Asian American; Hispanic; Native Hawaiian; Other/Multi- } \\
\text { racial }\end{array}$ \\
\hline Gender & Male; Female \\
\hline \multicolumn{2}{|l|}{ Cessation self-efficacy } \\
\hline Motivation to quit & None; Low; Medium; High; Very High \\
\hline Confidence in quitting & None; Low; Medium; High; Very High \\
\hline \multicolumn{2}{|l|}{ Intervention readiness } \\
\hline Stage of change & $\begin{array}{l}\text { Do not plan to quit in next } 6 \text { months; Plan to quit in next } 6 \text { months; Plan to quit in next } 30 \text { days; Made } \\
\text { a serious quit attempt in past } 6 \text { months; Quit less than } 6 \text { months ago }\end{array}$ \\
\hline \multicolumn{2}{|l|}{ Smoking behavior } \\
\hline Cigarettes per day (CPD) & Minimum (1); Maximum (90) \\
\hline Time to first cigarette (TTFC) & $<30$ minutes; $>30$ minutes \\
\hline $\begin{array}{l}\text { Nicotine dependence composite } \\
\text { (CPD+TFC) }\end{array}$ & Minimum (2); Maximum (92) \\
\hline Treatment failure & Yes (Not present at follow up or did not quit); No \\
\hline
\end{tabular}

LEVEL 2

School demographics

Number of full time teachers Numeric Variable 
Table 1. Continued

\begin{tabular}{|c|c|}
\hline LEVEL 1 & RESPONSE OPTIONS \\
\hline Student-teacher ratio & Ratio \\
\hline Total student enrollment & Numeric Variable \\
\hline Enrollment by gender & Male; Female \\
\hline Enrollment by race/ethnicity & $\begin{array}{l}\text { White; African American; American Indian; Asian American; Hispanic; Native Hawaiian; Other/Multi- } \\
\text { racial }\end{array}$ \\
\hline School location & City; Suburban; Rural; Town \\
\hline \multicolumn{2}{|l|}{ School district demographics } \\
\hline Race & $\begin{array}{l}\text { White; African American; American Indian; Asian American; Hispanic; Native Hawaiian; Other/Multi- } \\
\text { racial }\end{array}$ \\
\hline Education & $\begin{array}{l}\text { Less than high school; High-school graduate; Some college; Bachelor's degree; Master's degree; } \\
\text { Professional school degree; Doctorate degree }\end{array}$ \\
\hline Employment & $\begin{array}{l}\text { Not in labor force; In labor force: civilian, employed; In labor force: civilian unemployed; In labor force: } \\
\text { armed forces }\end{array}$ \\
\hline $\begin{array}{l}\text { Poverty status (derived from } \\
\text { median household income) }\end{array}$ & At or above poverty level; Living in poverty \\
\hline \multicolumn{2}{|l|}{ School economics } \\
\hline Teachers employed & Number of full time teachers; Student/faculty ratio \\
\hline Type of school & Regular; Alternative; Vocational \\
\hline Title I & Yes; No \\
\hline Lunch eligibility & Free lunch program; Reduced lunch program \\
\hline
\end{tabular}

and data collection procedures. Refer to previously published trials for details ${ }^{31,34,35}$. The present study received Institutional Review Board (IRB) approval for exemption (45 CFR 46.101, b. 1).

It is important to point out that while the individual level cessation trials had an initial goal to evaluate the efficacy of the N-O-T program, the present investigation sought to understand treatment failure among cessation seeking adolescents, regardless of treatment type. Thus, treatment conditions are not compared in the present investigation. However, statistical analyses controlled for treatment group to account for a known source of variation in outcomes in all models. For the present investigation, treatment failure is operationally defined as not achieving. the primary goal of smoking cessation among all participants, measured 3-months post baseline.

School-level data were associated with the schools that participated in the adolescent smoking cessation trials in five States: FL, NC, WV, WI and NJ. Each school was uniquely geo-referenced by postal ZIP code, a National Center for Education StatisticsIdentification Number (NCES-ID), and a Federal Information Processing Standard code (FIPS). The NCES, a part of the US Department of Education, is charged with collecting, collating and analyzing data on the education systems and schools. The NCES maintains a publicly available database of school and school-district data. The study used the NCES-ID to gather school-specific data including enrollment, number of full-time teachers, student-teacher ratio, and students eligible for free or reduced lunch from the NCES database. FIPS codes provided access to the publicly available US Census Bureau database to gather school-district level data for each school, including education level of individuals within the district, employment levels, and percentage of the district population living in poverty. A separate database was constructed containing all school-level data. The final step was to form a relational sociospatial database that connected all separate databases: 1) individual-level data containing information on each participant in the adolescent smoking cessation trials - this database included the geo-referenced code indicating the participant's school where the cessation program was conducted; and 2) school-level data containing both NCES and US Census Bureau information.

\section{Measures}

Outcome variables

Treatment failure. Using the intent-to-treat 
(ITT) sample, participants were considered to have experienced failure to quit if they reported continuing smoking or were not available for followup at 3-months post baseline. Conservatively, analysis assumed that unavailable participants continued to smoke, accounting for $27 \%$ of the treatment failure sample ${ }^{34,36}$. The study uniquely applied 'treatment failure', unlike the majority of tobacco cessation studies that commonly focus on quit rates ${ }^{9,37-39}$. Such an approach was intended to uncover important previously unknown information on the reasons why cessation treatments failed with adolescents who are regarded most at risk.

\section{Predictor variables}

The study included predictor variables that are well established in previous trials of the team and in other existing tobacco control literature ${ }^{34,35}$. Specifically, the model included factors associated with adolescent tobacco use, based on individual-level (Level-1) variables and school-level (Level-2) variables that convey information typically used to characterize school environments ${ }^{1,11,14-16,35,40-42}$.

\section{Individual-level variables}

Individual-level variables included basic demographic information (e.g. age, gender, race/ ethnicity), nicotine dependence, cessation selfefficacy, stages of change, and type of treatment program ${ }^{10,37,38,41-50}$. Nicotine dependence was constructed using a composite of smoking involvement and nicotine addiction by combining two variables that showed high collinearity: 1) Cigarettes per day (CPD), and 2) Time to first cigarette (TTFG). These two items accounted for the majority of variance in the Fagerström Test for Nicotine Dependence (FTND) ${ }^{51}$. CPD has traditionally been used as an indicator of smoking involvement and exposure (e.g. pack-years). TTFC has been shown to be highly related to: nicotine dependence, exposure to nicotine and carcinogens in both adolescent daily and non-daily smokers, and cessation outcomes among adolescents ${ }^{36,52-54}$ (Table $1)$.

\section{School-level variables}

Items selected for the school domain related to school location, school size, school-district size and demographics, and school economic status as derived from the NCES database ${ }^{55-58}$ (Table 1 ). Specifically, school demographics included locale, through school name and ZIP code, and was broadly classified as: a) city, b) rural, c) suburban, or d) town; while school size included: a) number of fulltime teachers, b) student-teacher ratio, and c) total number of students. School district demographics included: a) percentage of school district population with no high-school diploma, b) percentage of school district population unemployed, and c) percentage of school district population at or below the poverty level. Finally, school economic status included: a) percentage of school eligible for free lunch, and b) percentage of school eligible for reduced lunch.

\section{Analysis}

Data within the newly formed socio-spatial database were linked for analyses using the HLM7 software, matching individual- and school-level data on the school identifying codes (i.e. NCES-ID and FIPS $)^{59}$. Hierarchical Linear Modeling (HLM) analyses were conducted to determine the effect of school-level factors on individual-level cessation treatment outcomes (i.e. failed treatment vs treatment success). Because the outcome variable was dichotomous, Bernoulli models for bivariate outcomes were used. The purpose of these analyses was two-fold: 1) to examine the relationship between an adolescent's individual risks and cessation treatment failure, while controlling for other variables associated with cessation outcomes (e.g. age, race, gender, treatment group [intensive versus brief]), and 2) to determine if the Level-1 relationships were affected by school-level variables, as shown in Figure 1.

The initial step tested an unconstrained (i.e. null) model to confirm that the variability in the outcome of cessation failure was significantly different from zero. Next, a random intercepts model examined the relationships between the Level-1 predictor/control variables and the outcome. Based on the results of the random intercept model, the model removed any Level-1 predictor/control variables that were not significantly related to the outcome from subsequent analyses. Next, a means-as-outcomes model examined how Level-2 variables predicted 
the Level-1 outcome (with no Level-1 predictor/ control variables in the models). Finally, a random intercepts and slopes model explored interactions between the Level-1 and Level-2 variables. All analyses were conducted using HLM7 statistical software $^{59}$.

\section{RESULTS}

Adolescent smokers seeking school-based cessation treatment provided the Level-1 data. Participants were moderately addicted daily smokers $(\mathrm{M}=12.1 \mathrm{CPD}$ for weekdays, $\mathrm{SD}=11.1$; $\mathrm{M}=18.2$ CPD for weekends, SD=13.7). Refer to Table 2 for detailed characteristics among adolescents who experienced successful $(21.3 \%)$ versus failed treatment $(78.7 \%)$. Cessation intervention was offered in 807 schools from 5 States over 12 years (1997-2009), serving as the source of the Level-2 data. A total of 346 schools were located in Florida, 11 in North Carolina, 105 in New Jersey, 194 in Wisconsin and 151 in West Virginia. The schools were identified as being located in a city $(n=144)$, rural area $(n=187)$, suburban area $(n=268)$ or a town $(n=108)$. Refer to Table 3 for additional school characteristics.

Results showed significant variance in the cessation treatment failure variable by Level-2 group $\left[\mathrm{x}^{2}(259)=430.0, \mathrm{p}<0.001\right]$ (Table 4$)$. The interclass correlation (ICC) determined what part of the variance in cessation outcome was attributable to the individual-level (Level-1) and which part was attributable to the group-level (Level-2). The ICC was 0.102 , suggesting that $10 \%$ of the variation in cessation treatment failure occurred at the school-level and $90 \%$ of the variation occurred at the individual-level or elsewhere. Subsequent models were conducted to examine which variables contributed to the explained variance at each level. Given variance at both the individual- and schoollevels, the random intercepts model then entered several Level-1 predictor/control variables into the Level-1 model predicting treatment failure. The initial model included the following: 1) age, 2) gender, 3) nicotine dependence (CPD+TTFC), 4) treatment type assignment, and 5) cessation selfefficacy. Based on the initial model run, age and gender were removed as they were non-significant predictors of the outcome. The final random
Table 2. Participant sample characteristics

\begin{tabular}{|c|c|c|c|c|}
\hline \multirow[b]{2}{*}{ LEVEL I VARIABLES } & \multicolumn{2}{|c|}{$\begin{array}{c}\text { Treatment } \\
\text { Success } \\
21.3 \% \\
(n=1881)\end{array}$} & \multicolumn{2}{|c|}{$\begin{array}{l}\text { Treatment } \\
\text { Failure } \\
78.7 \% \\
(\text { (n-6971) }\end{array}$} \\
\hline & $\%$ & n & $\%$ & n \\
\hline \multicolumn{5}{|l|}{ DEMOGRAPHICS } \\
\hline \multicolumn{5}{|l|}{ Age $^{*}$} \\
\hline 11 & 0.2 & 3 & 0 & 0 \\
\hline 12 & 0.6 & 511 & 0.4 & 27 \\
\hline 13 & 2.5 & 43 & 1.7 & 107 \\
\hline 14 & 11.1 & 193 & 8.6 & 550 \\
\hline 15 & 25.2 & 437 & 23.0 & 1474 \\
\hline 16 & 29.7 & 515 & 29.1 & 1859 \\
\hline 17 & 21.2 & 368 & 25.8 & 1652 \\
\hline 18 & 8.1 & 141 & 10.4 & 665 \\
\hline 19 & 1.2 & 21 & 1.0 & 62 \\
\hline \multicolumn{5}{|l|}{ Gender } \\
\hline Female & 56.1 & 1054 & 56.3 & 3916 \\
\hline Male & 43.9 & 826 & 43.7 & 3038 \\
\hline \multicolumn{5}{|l|}{ Grade $^{*}$} \\
\hline 6 & 0.4 & 7 & 0.2 & 11 \\
\hline 7 & 1.5 & 24 & 0.9 & 49 \\
\hline 8 & 3.7 & 59 & 2.1 & 120 \\
\hline 9 & 26.4 & 418 & 22.9 & 1320 \\
\hline 10 & 29.0 & 460 & 27.2 & 1566 \\
\hline 11 & 24.4 & 387 & 27.4 & 1577 \\
\hline 12 & 14.6 & 231 & 19.4 & 1120 \\
\hline \multicolumn{5}{|l|}{ Race $^{*}$} \\
\hline White & 72.3 & 1216 & 79.5 & 4946 \\
\hline African American & 5.7 & 96 & 2.9 & 178 \\
\hline American Indian & 1.7 & 28 & 1.4 & 88 \\
\hline Asian American & 1.2 & 20 & 1.5 & 95 \\
\hline Hispanic & 13.7 & 230 & 9.3 & 576 \\
\hline Native Hawaiian & 0.1 & 1 & 0.4 & 26 \\
\hline Other & 5.3 & 90 & 4.9 & 306 \\
\hline Bi-racial & 0.1 & 2 & 0.1 & 7 \\
\hline
\end{tabular}

\section{CESSATION SELF-EFFICACY}

Motivation to quit *

None

$\begin{array}{llll}3.5 & 21 & 6.5 & 181\end{array}$

Low

Medium

13.3

High

39.6

79

20.2

29.6

235

45.3

Very high

14.0

176

21.4

Confidence to quit*

None

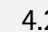

Low

Medium

High

$\begin{array}{llll}4.2 & 24 & 6.7 & 177\end{array}$

$\begin{array}{llll}19.6 & 111 & 26.6 & 702\end{array}$

$\begin{array}{llll}40.5 & 229 & 43.5 & 1146\end{array}$

Very high

21.2

Stages of change*

Do not plan to quit smoking in next 6 months
565

1264

598

182 
Table 2. Continued

\begin{tabular}{|c|c|c|c|c|}
\hline \multirow[b]{2}{*}{ LEVEL I VARIABLES } & \multicolumn{2}{|c|}{$\begin{array}{c}\text { Treatment } \\
\text { Success } \\
21.3^{\circ} \\
(\text { In } 1881)\end{array}$} & \multicolumn{2}{|c|}{$\begin{array}{l}\text { Treatment } \\
\text { Failure } \\
78.7^{\circ} \% \\
(n-6971)\end{array}$} \\
\hline & $\%$ & n & $\%$ & n \\
\hline $\begin{array}{l}\text { Plan to quit smoking in the next } \\
6 \text { months }\end{array}$ & 40.9 & 259 & 45.1 & 1447 \\
\hline Plan to quit in the next 30 days & 30.0 & 190 & 20.1 & 643 \\
\hline $\begin{array}{l}\text { Made a serious attempt in past } 6 \\
\text { months }\end{array}$ & 14.7 & 93 & 13.5 & 432 \\
\hline Quit less than 6 months ago & 6.5 & 41 & 4.0 & 128 \\
\hline \multicolumn{5}{|l|}{ SMOKING BEHAVIOR } \\
\hline & Mean & SD & Mean & SD \\
\hline $\begin{array}{l}\text { Nicotine Dependence Composite } \\
\text { (TTFC + CPD) Baseline }\end{array}$ & 24.44 & 19 & 29.97 & 17 \\
\hline
\end{tabular}

Table 3. School characteristics

\begin{tabular}{|c|c|c|c|c|}
\hline LEVEL 2 VARIABLES & $\begin{array}{l}\text { City } \\
\mathbf{N}=111\end{array}$ & $\begin{array}{l}\text { Rural } \\
\mathrm{V}=187\end{array}$ & $\begin{array}{l}\text { Suburb } \\
\text { V } 268\end{array}$ & $\begin{array}{l}\text { Town } \\
\mathrm{V}=108\end{array}$ \\
\hline \multicolumn{5}{|c|}{ School demographics/economics } \\
\hline Full time teachers+ & $77(37)$ & $59(36)$ & $90(36)$ & $52(22)$ \\
\hline Student-teacher ratio+ & $\begin{array}{r}17 \\
(3.27)\end{array}$ & $\begin{array}{r}15 \\
(3.23)\end{array}$ & $17(7.2)$ & $16(2.4)$ \\
\hline Total student enrolled+ & $\begin{array}{l}1339 \\
(716)\end{array}$ & $\begin{array}{r}962 \\
(715)\end{array}$ & $\begin{array}{l}1593 \\
(780)\end{array}$ & $\begin{array}{r}848 \\
(394)\end{array}$ \\
\hline Free lunch eligible & $40 \%$ & $34 \%$ & $35 \%$ & $34 \%$ \\
\hline Reduced lunch eligible & $7 \%$ & $7 \%$ & $7 \%$ & $7 \%$ \\
\hline \multicolumn{5}{|c|}{ School district demographics } \\
\hline $\begin{array}{l}\text { Per cent of population } \\
\text { without high-school } \\
\text { diploma }\end{array}$ & $11.51 \%$ & $15.57 \%$ & $12.44 \%$ & $16 \%$ \\
\hline $\begin{array}{l}\text { Per cent of population } \\
\text { unemployed }\end{array}$ & $5.8 \%$ & $5 \%$ & $6.4 \%$ & $5 \%$ \\
\hline $\begin{array}{l}\text { Per cent of population } \\
\text { living below poverty level }\end{array}$ & $20 \%$ & $22 \%$ & $18 \%$ & $24 \%$ \\
\hline
\end{tabular}

Table 4. Predictors of cessation self-efficacy and treatment failure by level

B SE P

Level 1 Variables predicting treatment failure

$\begin{array}{lrrr}\text { Treatment } & -0.41 & 0.10 & <0.001 \\ \text { Nicotine dependence } & 0.02 & 0.01 & 0.01 \\ \text { Cessation self-efficacy } & -0.40 & 0.10 & <0.001\end{array}$

Level 2 Variables predicting treatment failure

$\begin{array}{llll}\text { Less than high-school diploma } & 0.001 & 0.003 & 0.02\end{array}$

$\begin{array}{llll}\text { Student teacher ratio } & 0.003 & 0.001 & 0.008\end{array}$

Random slopes/intercept models of Level-2 interactions on cessation self-efficacy and treatment failure

$\begin{array}{lrrr}\text { Free lunch eligible } & 0.01 & 0.001 & 0.001 \\ \text { Reduced lunch eligible } & 0.01 & 0.0001 & 0.008\end{array}$

intercepts model suggested that treatment type ( $\beta=-0.41, \mathrm{SE}=0.10, \mathrm{p}<0.001)$, nicotine dependence $(\beta=0.02, \mathrm{SE}=0.01, \mathrm{p}=0.01)$ and cessation selfefficacy $(\beta=-0.4, \mathrm{SE}=0.10, \mathrm{p}<0.001)$ all predicted cessation failure. Specifically, as demonstrated previously ${ }^{60,61}$, intensive treatment (i.e. $\mathrm{N}-\mathrm{O}-\mathrm{T}$ ) and greater cessation self-efficacy predicted a higher likelihood of treatment success, while nicotine dependence predicted a greater likelihood of treatment failure.

Next, the impact of several Level-2 predictors on cessation failure was examined. These models did not include the Level-1 predictors of outcomes (treatment group, nicotine dependence, or cessation self-efficacy). Level-2 model variables included: $1)$ percentage of school district population with no high-school diploma, 2) percentage of school district population unemployed, 3) percentage of school district population at or below the poverty level, 4) number of full-time teachers, 5) studentteacher ratio, 6) total number of students, 7) percentage of school eligible for free lunch, 8) percentage of school eligible for reduced lunch, and 9) school locale. Results demonstrate that the percentage of school-district population with less than a high-school diploma $(\beta=0.01, \mathrm{SE}=0.003$, $\mathrm{p}=0.02)$ and the student-teacher ratio $(\beta=0.003$, $\mathrm{SE}=0.001, \mathrm{p}=0.008)$ predict cessation failure. Participants in schools in districts with lower rates of residents receiving high-school diplomas and in schools with a high ratio of students to teachers were more likely to experience higher cessation failure rates.

Finally, a random slopes and intercepts model was conducted to examine how Level-2 variables interact with the Level-1 relationship between predictor/controls and cessation treatment failure. Both free lunch eligible $(\beta=0.01, \mathrm{SE}=0.001$, $\mathrm{p}=0.001)$ and reduced lunch eligible $(\beta=0.01$, $\mathrm{SE}=0.0001, \mathrm{p}=0.008)$ interacted with the relationship between cessation self-efficacy and treatment failure (Table 4). Specifically, individuals from schools with higher percentages of free and reduced lunch eligible students were more likely to experience failed treatment regardless of their level of cessation self-efficacy. There were no other significant interactions between Level-2 and Level-1 variables. 


\section{DISCUSSION}

While findings showed a higher than average percent of adolescents quit $(21.3 \%)$, most did not report success. The present study found a significant (10\%) proportion of the variance in cessation outcomes was attributable to the specific conditions of the school environment, regardless of an individual adolescent's cessation self-efficacy. Treatment-seeking adolescent smokers in school districts with a large percentage of the population having less than a high-school education were more likely to experience failed treatment. The same was true for adolescents from schools with a higher ratio of students to teachers. Finally, the strength of the relationship between adolescent smokers' propensity to quit and treatment success was weakened among individuals attending schools with higher percentages of students eligible for free or reduced lunch programs. Free or reduced price lunch eligibility corresponds to US Federal poverty levels, and as such is highly associated with disadvantage.

Taken together, these findings reflect conditions that are well-established indicators of schools that are underfunded and affected by socio-economic disadvantage ${ }^{62}$. Results are especially meaningful in light of the fact that adolescent smoking is more prevalent in areas of low socio-economic status ${ }^{63,64}$. Greater treatment failure in individuals that have high needs for tobacco cessation underscores the importance of policy and programmatic scrutiny. The novel finding is not that adolescents in resourcelimited school districts are at increased risk of failure but that the likelihood is high despite their individual motivations to quit. This is supported by other research showing that lower SES leads to the development of lower self-efficacy and a lower propensity to quit smoking ${ }^{65}$. Similarly, measures of disadvantage account for nearly one-third of the class differential in smoking ${ }^{66}$. The findings suggest that adolescent-focused smoking cessation policies should consider the importance of social and economic context in quitting smoking. Past research would predict that given two adolescents with an identical motivation to quit smoking in a cessation program, the adolescent with the greater belief in his or her ability to quit smoking (i.e. higher cessation self-efficacy) would be more likely to succeed with quitting smoking ${ }^{67}$. Our findings suggest that it is not that simple and that even with high motivation there is a heightened need for cessation programs to shield individual self-efficacy by buffering adolescents from the proximal effects of school- or area-level socioeconomic disadvantage.

Some of the study's identified school-related factors and conditions are more malleable than others, with implications for policy makers, principals, teachers or other practitioners who implement school-based tobacco cessation programming. A high student-teacher ratio, as was found in the present study, is often an indicator of proportionately underfunded schools or school districts ${ }^{58,68}$. Demonstrating the impact of schoollevel socio-economic disadvantage on tobacco cessation programming provides evidence for policy makers to advocate for increased funding in affected school districts, particularly those experiencing a disproportionate burden of tobaccorelated health disparities. High teacher workloads may also suggest the need to establish programs to enhance student-teacher relationships as a means to improve student health. Studies show that low-income students who have strong teacherstudent relationships have higher academic achievement ${ }^{69,70}$. Similarly, cessation programming in underfunded schools may need to supplement programs with tailored or 'wrap-around' services such as special advisors, adult or peer mentors, or other assigned resources to foster positive relationships among adolescents who enroll in cessation programs. These types of relationships could also have bearing on self-efficacy of disadvantaged students.

Adolescents who attend schools within socioeconomically disadvantaged districts are likely to be among adults with less than a high-school education. Evidence suggests that these adolescents in turn may have high exposure to peer and family smoking, and may see tobacco modeled as a means for coping with economic or financial stress ${ }^{71}$. Therefore, cessation programming may be supplemented with life skills content and coping techniques to buffer the influence of life stressors on adolescent substance abuse $^{72}$.

A few limitations should be considered when interpreting the findings. Important individual risk factors for continued tobacco use, such as 
stress and depression, were not measured in this study. Other potentially important individual- and school-level factors, such as student achievement and school activities, also were not captured. Peer level influence was not included due to a lack of data. It is also noteworthy that the menu of tobacco products available today, including electronic cigarettes, were not available or widely used in the US during the course of the original studies. These and other possible risk factors and confounding variables not measured or accounted for in this study warrant caution when generalizing the findings across US adolescents. Further study with the inclusion of additional factors not measured in this study may lead to more or less variance in cessation outcomes explained by the school environment or higher State-level influences. The $10 \%$ variance found in the present study is conservative.

Analyses assumed that adolescents who did not attend the 3-month follow-up continued to smoke. The study did not acknowledge reduction as a positive outcome. While we assert the importance of cigarette reduction as an outcome in real-world implementation, this study was explicitly interested in pinpointing reasons for cessation treatment failure. Moreover, because reasons for participant attrition at follow-up (i.e. missing data) were unknown, the analyses applied the most conservative ITT approach by assuming continued smoking. This approach was also consistent with the study goal to explore failed cessation.

A final caution is the periodic collection of census data at 5-year intervals. This approach dictated that the study use census data closest in time to the years in which the trials were conducted. This may seem like an inexact estimation, but the pooled 5-year sample size provides the most reliable estimate for small populations/geographic areas, such as school districts and ZIP codes $^{73}$. Moreover, despite having data over an extended period of time for temporal estimation, the design remains cross-sectional, and thereby findings shouldn't be used to draw causal conclusions.

\section{CONCLUSIONS}

Other studies ${ }^{9,11,14,74}$ have investigated the role of the school environment on individual adolescent smoking prevalence but have not pinpointed the predictive contribution of school-district economic disadvantage on an individual's ability to quit smoking. The current study suggests that specific place-based factors, such as school-level socio-economic disadvantage, may reduce the benefits of tobacco cessation interventions, despite an adolescent's high level of self-efficacy to quit. Importantly, this finding may be applicable to other school-based wellness programs (e.g. obesity, substance abuse, physical inactivity). To that end, adolescent smoking cessation programming, particularly when schoolbased, may: a) consider how to buffer the schoollevel factors that place adolescents at higher risk of failed cessation treatment, and b) be required in greater concentration in locations of socio-economic disadvantage.

Data should not be interpreted to mean that students in poor school districts are doomed to cessation failure. Rather, it draws attention to opportunities to minimize these proximal effects on individual cessation outcomes through tailoring of cessation programs to be cognizant and responsive to these factors.

In summary, the study shed light on the impact that a change in one socio-ecological level can have on a level nested within it. A sociospatial model helped to identify not only the various interactions that occurred at the schoollevel domain but more precisely what specific factors were the greatest contributors. While $10 \%$ may seem small, it represents a part of the environmental landscape that may be modified to improve cessation outcomes. Imagine the improvements in cessation treatment programming if research could likewise uncover or explain the specific contributing domains and factors within those domains for the remaining 90\%. Such a vision of tobacco control allows for an active and predictive consideration of multi-level contextual influences on tobacco use related to space and place. It is through this type of approach that we may achieve evidence for the most effective mix of policy, program and economic factors that support or impede tobacco control initiatives. Practitioners and policy makers alike may consider this evidence as supporting the need for policy and practice that are conscious of 'synchronous' 
multi-level influences on adolescent smoking cessation treatment outcomes.

\section{REFERENCES}

1. Singh T, Arrazola RA, Corey CG, Husten CG, Neff LJ, Homa DM, et al. Tobacco Use Among Middle and High School Students--United States, 2011-2015. MMWR Morb Mortal Wkly Rep. 2016;65(14):361-7. doi: 10.15585/mmwr.mm6514a1.

2. Arrazola RA, Kuiper NM, Dube SR. Patterns of current use of tobacco products among U.S. high school students for 2000-2012--findings from the National Youth Tobacco Survey. J Adolesc Health. 2014;54(1):54-60 e9. doi: 10.1016/j.jadohealth.2013.08.003

3. Cigarette smoking among adults and trends in smoking cessation-United States, 2008. MMWR Morb Mortal Wkly Rep. 2009;58(44):1227-32.Centers for Disease Control and Prevention (CDC).

4. Lee YO, Hebert CJ, Nonnemaker JM, Kim AE. Youth tobacco product use in the United States. Pediatrics. 2015;135 (3):409-15. doi: 10.1542/peds.2014-3202

5. West R, McEwen A, Bolling K, Owen L. Smoking cessation and smoking patterns in the general population: a 1-year follow-up. Addiction. 2001;96(6):891-902. doi: 10.1111/j.1360-0443.2009.02735.x.

6. Karpinski JP, Timpe EM, Lubsch L. Smoking cessation treatment for adolescents. J Pediatr Pharmacol Ther. 2010;15(4):249-63.

7. Milton MH, Maule CO, Yee SL, Backinger C, Malarcher AM, Husten CG. Youth tobacco cessation: A guide for making informed decisions. In Youth tobacco cessation: a guide for making informed decisions. Centers for Disease Control and Prevention (CDC); 2004.

8. Marshall L, Schooley M, Ryan H, Cox P, Easton A, Healton C, et al. Youth tobacco surveillance-United States, 20012002. MMWR Surveill Summ. 2006;55(3):1-56.

9. Curry SJ, Mermelstein RJ, Emery SL, Sporer AK, Berbaum ML, Campbell RT, et al. A national evaluation of community-based youth cessation programs: end of program and twelve-month outcomes. Am J Community Psychol. 2013;51(1-2):15-29. doi: 10.1007/s10464-012-9496-8

10. Sussman S. Effects of sixty six adolescent tobacco use cessation trials and seventeen prospective studies of self-initiated quitting. Tobacco Induced Diseases. 2002;1(1):35-81. doi: 10.1186/1617-9625-1-1-35

11. Lovato C, Watts A, Brown KS, Lee D, Sabiston C, Nykiforuk C, et al. School and community predictors of smoking: a longitudinal study of Canadian high schools. Am J Public Health. 2013;103(2):362-8. doi: 10.2105/AJPH.2012.300922

12. Borland BL, Rudolph JP. Relative effects of low socioeconomic status, parental smoking and poor scholastic performance on smoking among high school students.
Social Science \& Medicine (1967). 1975;9(1):27-30. doi: 10.1016/0037-7856(75)90155-9

13. Aveyard P, Markham WA, Lancashire E, Almond J, Griffiths R, Cheng KK. Is interschool variation in smoking uptake and cessation due to differences in pupil composition? A cohort study. Health Place. 2005;11(1):55-65. doi: 10.1016/j.healthplace.2004.02.001

14. Piontek D, Buehler A, Donath C, Floeter S, Rudolph U, Metz K, et al. School context variables and students' smoking. Testing a mediation model through multilevel analysis. Eur Addict Res. 2008; 14(1):53-60. doi: 10.1159/000110411

15. Piontek D, Buehler A, Rudolph U, Metz K, Kroeger C, Gradl S, et al. Social contexts in adolescent smoking: does school policy matter? Health Education Research. 2008; 23(6):1029-38. doi:10.1093/her/cym063

16. Wen M, Van Duker H, Olson LM. Social contexts of regular smoking in adolescence: towards a multidimensional ecological model. J Adolesc. 2009; 32(3):671-92. doi: 10.1016/j.adolescence.2008.06.008

17. Fergusson DM, Horwood LJ, Boden JM, Jenkin G. Childhood social disadvantage and smoking in adulthood: Results of a 25-year longitudinal study. Addiction. $2007 ; 102(3): 475-82$. doi: 10.1111/j.1360-0443.2006.01729.x

18. Non AL, Rewak M, Kawachi I, Gilman SE, Loucks EB, Appleton AA, et al. Childhood social disadvantage, cardiometabolic risk, and chronic disease in adulthood. American Journal of Epidemiology. 2014;180(3):26371. doi: 10.1093/aje/kwu127

19. Non AL, Román JC, Gross CL, Gilman SE, Loucks EB, Buka SL, et al. Early childhood social disadvantage is associated with poor health behaviours in adulthood. Annals of Human Biology. 2016; 43(2):144-53. doi: 10.3109/03014460.2015.1136357

20. Borland R, Young D, Coghill K, Zhang JY. The tobacco use management system: Analyzing tobacco control from a systems perspective. American Journal of Public Health. 2010;100(7):1229-36. doi: 10.2105/AJPH.2009.165910

21. Best A, Clark PI, Leischow SJ, Trochim WM. Greater than the sum: Systems thinking in tobacco control. 2007. https://cancercontrol.cancer.gov/brp/tcrb/ monographs/18/m18_complete.pdf. Accessed June $23,2017$.

22. Silbereisen RK. Development and ecological context: History of the psychological science in a personal view and experience - An interview with Urie Bronfenbrenner. Psychologie in Erziehung und Unterricht. 2006;53(1):63-71.

23. Davis R, Gilpin E, Loken B, Viswanath K, Wakefield M., eds. The Role of the Media in Promoting and Reducing Tobacco Use. Tobacco Control Monograph No.19. Bethesda, MD: U.S. Department of Health and Human 
Services, National Institutes of Health, National Cancer Institute. NIH Pub. No. 07-6242, 2009:357-428

24. Evaluating ASSIST: A Blueprint for Understanding State-Level Tobacco Control. Bethesda, MD: National Cancer Institute; October 2006. Tobacco Control Monograph 17, National Institutes of Health publication 06-6058.

25. Pierce JP, Messer K, James LE, White MM, Kealey S, Vallone DM, et al. Camel No. 9 Cigarette-Marketing Campaign Targeted Young Teenage Girls. Pediatrics. 2010;125(4):619-26. doi:10.1542/peds.2009-0607

26. Bailey SL, Ennett ST, Ringwalt CL. Potential mediators, moderators, or independent effects in the relationship between parents former and current cigarette use and their children's cigarette use. Addictive Behaviors. 1993;18(6):601-21. doi:10.1016/0306-4603(93)90015-2

27. Dalton MA, Sargent JD, Beach ML, Titus-Ernstoff L, Gibson JJ, Ahrens MB, et al. Effect of viewing smoking in movies on adolescent smoking initiation: a cohort study. Lancet. 2003;362(9380):281-5. doi: 10.1016/S0140-6736(03)13970-0

28. Kobus K. Peers and adolescent smoking. Addiction. 2003;98 Suppl 1(s 1):37-55. doi:10.1046/j.1360-0443.98.s1.4.x

29. Fagan P, Augustson E, Backinger CL, O’Connell ME, Vollinger Jr RE, Kaufman A, et al. Quit attempts and intention to quit cigarette smoking among young adults in the United States. American Journal of Public Health. 2007;97(8):1412-20. doi:10.2105/AJPH.2006.103697

30. Franks A, Kelder S, Dino G, Horn K, Gortmaker S, Wiecha J. School-based programs: lessons learned from CATCH, Planet Health, and Not-On-Tobacco. Preventing Chronic Disease. 2007;4(2, A33):1545-151.

31. Horn K, Dino G, Kalsekar I, Mody R. The impact of Not on Tobacco on teen smoking cessation end-ofprogram evaluation results, 1998 to 2003. Journal of Adolescent Research. 2005;20(6):640-61. doi: 10.1177/0743558405274891

32. Horn K, McGloin T, Dino G, Manzo K, McCracken L, Shorty L, et al. Quit and reduction rates for a pilot study of the American Indian Not On Tobacco (NOT) program. Prev Chronic Dis. 2005;2(4):A13.

33. Dino G, Horn K, Goldcamp J, Fernandes A, Kalsekar I, Massey C. A 2-year efficacy study of Not On Tobacco in Florida: An overview of program successes in changing teen smoking behavior. Preventive Medicine. 2001;33(6):600-5. doi: 10.1006/pmed.2001.0932

34. Branstetter SA, Horn K, Dino G, Zhang J. Beyond quitting: predictors of teen smoking cessation, reduction and acceleration following a school-based intervention. Drug Alcohol Depend. 2009;99(1-3):1608. doi:10.1016/j.drugalcdep.2008.07.011

35. Horn K, Dino G, Branstetter B, Zhang J, Kelley G, Noerachmanto $\mathrm{N}$, et al. A profile of teen smokers who volunteered to participate in school-based smoking intervention. Tob Induc Dis. 2008; 4(1):6. doi: 10.1186/1617-9625-4-6

36. Mercincavage M, Branstetter SA, Muscat JE, Horn KA. Time to first cigarette predicts cessation outcomes in adolescent smokers. Nicotine Tob Res. 2013;15(12):1996-2004. doi: 10.1093/ntr/ntt087

37. Ellickson PL, McGuigan KA, Klein DJ. Predictors of late-onset smoking and cessation over 10 years. J Adolesc Health. 2001;29(2):101-8. doi:10.1016/S1054-139X(00)00199-3

38. Emmons KM, Wechsler H, Dowdall G, Abraham M. Predictors of smoking among US college students. American Journal of Public Health. 1998;88(1):104-7. doi: 10.2105/ajph.88.1.104

39. Joffe A, McNeely C, Colantuoni E, An MW, Wang W, Scharfstein D. Evaluation of school-based smoking-cessation interventions for self-described adolescent smokers. Pediatrics. 2009;124(2):e187-94. doi:10.1542/peds.2008-2509

40. Lovato CY, Zeisser C, Campbell HS, Watts AW, Halpin P, Thompson M, et al. Adolescent smoking: effect of school and community characteristics. Am J Prev Med. 2010;39(6):507-14. doi: 0.1016/j.amepre.2010.08.019

41. Tyas SL, Pederson LL. Psychosocial factors related to adolescent smoking: a critical review of the literature. Tob Control. 1998;7(4):409-20. doi:10.1136/tc.7.4.409

42. Zhu SH, Sun JC, Billings SC, Choi WS, Malarcher A. Predictors of smoking cessation in US adolescents. American Journal of Preventive Medicine. 1999;16(3):202-7.

43. Audrain-McGovern J, Halbert CH, Rodriguez D, Epstein LH, Tercyak KP. Predictors of participation in a smoking cessation program among young adult smokers. Cancer Epidemiology Biomarkers \& Prevention. 2007;16(3):617-9. doi: 10.1158/1055-9965.EPI-060791

44. Curry SJ, Emery S, Sporer AK, Mermelstein R, Flay BR, Berbaum M, et al. A national survey of tobacco cessation programs for youths. Am J Public Health. 2007;97(1):171-7.

45. Mermelstein R. Teen smoking cessation. Tobacco Control. 2003. 12 Suppl 1: i25-i34. doi:10.1136/tc.12.suppl_1.i25

46. Niaura R, Abrams DB. Smoking cessation: progress, priorities, and prospectus. J Consult Clin Psychol. 2002;70(3):494-509. doi: 10.1037//0022-006X.70.3.494

47. Orleans CT, Arkin EB, Backinger CL, Best A, Crossett L, Grossman D, et al. Youth Tobacco Cessation Collaborative and National Blueprint for Action. Am J Health Behav. 2003;27 Suppl 2(1):S103-19. doi: 10.5993/ajhb.27.1.s2.2

48. Sussman S, Sun P, Dent CW. A meta-analysis of teen cigarette smoking cessation. Health Psychol. 2006;25(5):549-57. doi: 10.1037/0278-6133.25.5.549 
49. Vink JM, Willemsen G, Boomsma DI. The association of current smoking behavior with the smoking behavior of parents, siblings, friends and spouses. Addiction. 2003;98(7):923-31. doi: 10.1046/j.1360-0443.2003.00405.x

50. Spek V, Lemmens F, Chatrou M, van Kempen S, Pouwer F, Pop V. Development of a smoking abstinence self-efficacy questionnaire. Int J Behav Med. 2013;20(3):444-9. doi:10.1007/s12529-012-9229-2

51. Etter J-F, Duc TV, Perneger TV. Validity of the Fagerstrom test for nicotine dependence and of the Heaviness of Smoking Index among relatively light smokers. Addiction. 1999;94(2):269-81. 10.1046/j.1360-0443.1999.94226910.x

52. Branstetter SA, Mercincavage M, Muscat JE. Time to first cigarette predicts 4-(methylnitrosamino)-1-(3pyridyl)-1-butanol (NNAL) in adolescent regular and intermittent smokers, National Health and Nutrition and Examination Survey ( NHANES) 2007-10. Addiction. 2014;109(6):1005-12. doi: 10.1111/add.12515

53. Branstetter SA, Muscat JE. Time to first cigarette and serum cotinine levels in adolescent smokers: National health and nutrition examination survey, 2007-2010. Nicotine and Tobacco Research. 2013;15(3):701-7. doi:10.1093/ntr/nts189

54. Covey LS, Hu MC, Weissman J, Croghan I, Adler L, Winhusen T. Divergence by ADHD subtype in smoking cessation response to OROS-methylphenidate. Nicotine and Tobacco Research. 2011;13(10):1003-8. doi:10.1093/ntr/ntr087

55. Alexander C, Piazza M, Mekos D, Valente T. Peers, schools, and adolescent cigarette smoking. Journal of Adolescent Health. 2001;29(1):22-30. doi:10.1016/S1054-139X(01)00210-5

56. Conrad KM, Flay BR, Hill D. Why children start smoking cigarettes: predictors of onset. British Journal of Addiction. 1992;87(12):1711-24. doi: 10.1111/j.1360-0443.1992.tb02684.x

57. Ellickson PL, Bird CE, Orlando M, Klein DJ, McCaffrey DF. Social context and adolescent health behavior: Does school-level smoking prevalence affect students' subsequent smoking behavior? Journal of Health and Social Behavior. 2003;44(4):525-35. doi: $10.2307 / 1519797$

58. Kena G, Musu-Gillette L, Robinson J, Wang X, Rathbun A, Zhang J, et al. The Condition of Education 2015. NCES 2015-144. National Center for Education Statistics; 2015.

59. Raudenbush S, Bryk A, Congdon R. HLM 7.01 for Windows [Hierarchical linear and nonlinear modeling software] 2013.

60. Dino G, Kamal K, Horn K, Kalsekar I, Fernandes A. Stage of change and smoking cessation outcomes among adolescents. Addictive Behaviors. 2004;29(5):935-40. doi:10.1016/j.addbeh.2004.01.004
61. Horn K, Fernandes A, Dino G, Massey CJ, Kalsekar I. Adolescent nicotine dependence and smoking cessation outcomes. Addictive Behaviors. 2003;28(4):769-76. doi:10.1016/S0306-4603(02)00229-0

62. Sirin SR. Socioeconomic status and academic achievement: A meta-analytic review of research. Review of Educational Research. 2005;75(3):417-53. doi: 10.3102/00346543075003417

63. Hiscock R, Bauld L, Amos A, Fidler JA, Munafò M. Socioeconomic status and smoking: a review. Annals of the New York Academy of Sciences. 2012;1248(1):10723. doi: 10.1111/j.1749-6632.2011.06202.x

64. Mathur C, Erickson DJ, Stigler MH, Forster JL, Finnegan Jr JR. Individual and neighborhood socioeconomic status effects on adolescent smoking: A multilevel cohort-sequential latent growth analysis. American Journal of Public Health. 2013;103(3):543-8. doi: 10.2105/ajph.2012.300830

65. Siahpush M, McNeill A, Borland R, Fong GT. Socioeconomic variations in nicotine dependence, selfefficacy, and intention to quit across four countries: findings from the International Tobacco Control (ITC) Four Country Survey. Tobacco control. 2006 Jun 1;15( suppl 3):iii71-5. doi:10.1136/tc.2004.008763

66. Layte R, Whelan CT. Explaining social class inequalities in smoking: the role of education, self-efficacy, and deprivation. European Sociological Review. 2008 Mar 25;25(4):399-410. doi: 10.1093/esr/jcn022

67. Romanowich P, Mintz J, Lamb RJ. The relationship between self-efficacy and reductions in smoking in a contingency management procedure. Experimental and clinical psychopharmacology. 2009 Jun;17(3):139. doi:10.1037/a0015842

68. Carey K. Education Funding and Low-Income Children: A Review of Current Research. 2002. Center on Budget and Policy Priorities.

69. Murray C. Parent and teacher relationships as predictors of school engagement and functioning among lowincome urban youth. Journal of Early Adolescence. 2009;29(3):376-404. doi:10.1177/0272431608322940

70. Roorda DL, Koomen HMY, Spilt JL, Oort FJ. The influence of affective teacher-student relationships on students' school engagement and achievement: A metaanalytic approach. Review of Educational Research. 2011;81(4):493-529. doi:10.3102/0034654311421793

71. Barreto SM, Giatti L, Casado L, de Moura L, Crespo C, Malta D. Contextual factors associated with smoking among Brazilian adolescents. J Epidemiol Community Health. 2012;66(8):723-9. doi:10.1136/jech.2010.122549

72. Sancassiani F, Pintus E, Holte A, Paulus P, Moro MF, Cossu G, et al. Enhancing the emotional and social skills of the youth to promote their wellbeing and positive development: a systematic review of universal schoolbased randomized controlled trials. Clinical Practice 
\& Epidemiology in Mental Health. 2015;11(1):21-40. doi: 10.2174/1745017901511010021

73. U.S. Census Bureau. A Compass for Understanding and Using American Community Survey Data. What General Data Users Need to Know. 2008, Washington, D.C.: U.S. Government Printing Office.

74. Leatherdale ST, Cole A. Examining the impact of changes in school tobacco control policies and programs on current smoking and susceptibility to future smoking among youth in the first two years of the COMPASS study: looking back to move forward. Tobacco Induced Diseases. 2015;13(1):8. doi:10.1186/s12971-015-0031-1

\section{ACKNOWLEDGEMENTS}

The authors acknowledge and thank Geri Dino PhD, as co-developer of the $\mathrm{N}-\mathrm{O}-\mathrm{T}$ program and as a contributing investigator to the original source trials.

\section{CONFLICTS OF INTEREST}

Author KA Horn was co-developer and evaluator of the cessation program ( ${ }^{\circ}$ American Lung Association's Not-On-Tobacco, N-O-T) that was a program component of the numerous original trials that generated the source data for the study discussed in this article. KA Horn and Branstetter were contributing investigators on most of the original trials. While the original trials were conducted with the express purpose of demonstrating the N-O-T program efficacy, the noted investigation capitalized on the combined source data to examine adolescent smokers experiencing failed treatment, regardless of treatment type. The original source trials were funded from multiple agencies and organizations. Horn holds no copyrights or trademarks for $\mathrm{N}-\mathrm{O}-\mathrm{T}$ and receives no financial remuneration for program distribution. The rest of the authors have also completed and submitted an ICMJE form for disclosure of potential conflicts of interest. The authors declare that they have no competing interests, financial or otherwise, related to the current work.

\section{FUNDING}

This work was supported by a grant from NIH-National Cancer Institute, proposal number: R01 CA169070-02S1. Authors KA Horn and S Branstetter are the Pls of the grant supporting the present study.

PROVENANCE AND PEER REVIEW

Not commissioned;

externally peer reviewed 